\title{
Proteína Tax (HTLV-I), probable factor patogénico y marcador del síndrome sicca que se asocia a HAM/TSP
}

\author{
Luis Cartier $\mathbf{R}^{\mathbf{1}}$, Carmen Vergara $\mathbf{R}^{\mathbf{l a}}$, Eugenio Ramírez $\mathbf{V}^{\mathbf{2 b}}$.
}

\section{Viral Tax protein expression in salivary glands of patients infected with human t-cell lymphotropic virus type I and Sicca Syndrome}

Background: Human T-cell lymphotropic virus type I (HTLV-I) is a retrovirus that influences cellular metabolism modifying biological responses. This results in oncogenic, degenerative or inflammatory changes. The myelopathy associated to HTLV-I or tropical spastic paraparesia (HAM/TSP) is a mainly degenerative response to the virus infection. On the other hand, Sjögren syndrome has an inflammatory appearance. The immunohistochemical study of CD-4, CD-8 and CD45 lymphocytes, metalloproteinase MMP-9 and viral Tax protein in pathological samples of salivary glands may help to differentiate primary from viral Sicca syndrome. Aim: To perform an immunohistochemical study of salivary glands of patients with HAM/TSP and Sicca syndrome and control subjects. Material and Methods: Pathological samples of salivary glands from 53 patients with HAM/TSP and Sicca syndrome and 10 control subjects, were studied. Immunohistochemistry was performed using antibodies against CD-4, CD-8 and CD-45 lymphocytes, metalloproteinase MMP-9 and viral Tax protein. Results: Only in patients with HAM/TSP and Sicca syndrome, the presence of Tax protein was observed in CD-4 and CD-8 lymphocytes and in glandular acini. Conclusions: Patients infected with HTLV-I express Tax protein in salivary glands. This finding has diagnostic and pathogenic implications (Rev Méd Chile 2005; 133: 1183-90).

(Key Words: Gene products, Tax; Human T-lymphotropic virus 1; Sjögren syndrome).

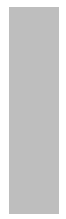

Recibido el 4 de enero, 2005. Aceptado el 7 de junio, 2005.

Trabajo financiado por Conicyt \# 1020328.

${ }^{1}$ Laboratorio de Neuropatología, Departamento de Ciencias Neurológicas, Escuela de Medicina, Universidad de Chile. ${ }^{2}$ Sección de Virología, Instituto de Salud Pública.

aTecnólogo Médico

bioquímico

Correspondencia a: Dr. Luis Cartier R. Luis Thayer Ojeda

717, Depto 52. E mail: lcartier@med.uchile.cl 
$\mathrm{E}$ virus linfotrópico humano tipo I (HTLV-I) es un virus ancestral en Sudamérica, presente desde hace miles de años entre la población amerindia de los Andes ${ }^{1}$. Es un retrovirus con acciones oncogénicas causante del linfoma $\mathrm{T}$ del adulto (ATL) ${ }^{2}$. También puede dañar el sistema nervioso central, desarrollando la mielopatía asociada a HTLV-I o paraparesia espástica tropical $(\mathrm{HAM} / \mathrm{TSP})^{3}$. Además, tiene cierta tendencia a instalarse en las glándulas exocrinas, hecho que queda de manifiesto por la capacidad infectiva de las mujeres portadoras del virus en la lactancia, también por su vinculación a una forma de síndrome de Sjögren (SS) que se desarrolla en los pacientes infectados con HTLV-I. Esta forma de SS puede presentarse aislada 0 asociarse con ATL 0 HAM/TSP. De hecho, la mayoría de los casos de HAM/TSP desarrollan una dacriosialopatía característica ${ }^{4}$. Este síndrome sicca de origen viral no resulta ser el único de origen infeccioso. Con alta frecuencia se ha vinculado el virus de la hepatitis $\mathrm{C}$ con $\mathrm{SS}^{5}$.

El motivo de este trabajo es el análisis histopatológico e histoquímico de glándulas salivares de cincuenta y tres pacientes HAM/TSP, portadores de un SS como parte del complejo sintomático que acompaña a la paraparesia espástica progresiva producida por el HTLV-I.

\section{MATERIAL Y MÉTODO}

Se estudió la biopsia de glándulas salivares de cincuenta y tres pacientes portadores de paraparesia espástica progresiva, originada por HTLV-I, que presentaban síndrome sicca. La definición clínica y virológica de los pacientes con HAM/TSP había sido establecida con anterioridad ${ }^{6-8}$. En todos los enfermos se definió con el test de Schirmer, la sequedad ocular, para decidir la biopsia de glándulas salivares menores. La calificación del SS fue establecida de acuerdo a los criterios del grupo europeo para el síndrome de Sjögren ${ }^{9}$.

Las muestras de glándulas salivares menores fueron tomadas en el Servicio de Maxilofacial del Hospital del Salvador y fijadas en Buoin. Tres de estos pacientes que llegaron al estudio necrópsico, tenían además muestras de glándulas submaxilares, al igual que los diez casos controles, que se originaron en muestras glandulares obtenidas de pacientes de autopsias que no tenían antecedentes de SS (como controles sanos). Los cortes histológicos se realizaron en material incluido en parafina y se tiñeron con HE y Gomori, que permitieron clasificar la intensidad de las lesiones de acuerdo a Chisholm y Mason. En el estudio inmunohistoquímico se identificaron linfocitos CD4-CD8 y CD45. Se estableció la actividad de la metaloproteinasa MMP-9 y se identificó la presencia de la proteína viral Tax en las estructuras glandulares. También se estudió el hígado de los tres pacientes con anatomía patológica, cuyos hallazgos se agregaron a esta investigación. Los pacientes concedieron un consentimiento informado de acuerdo a las normas del Comité de Ética del Hospital del Salvador y a las exigencias de Conicyt, aunque la biopsia de labio es un examen de rutina en el estudio del síndrome sicca.

El procedimiento inmunohistoquímico se inició con el bloqueo de la actividad de peroxidasas endógenas con $\mathrm{H}_{2} \mathrm{O}_{2}$ al $3 \%$ en metanol. Se lavó con solución tamponada de fosfatos y se aplicó suero no inmune al $10 \%$, para eliminar la actividad inespecífica del fondo. Se usó antiTax (anticuerpo monoclonal Lt-4 gentileza Dr. Shunro Sonada, Kagoshima, Japón) antiCD45, antiCD4 y antiCD8 (Dako), y anti MMP-9 (Chemicon). El revelado se realizó con el kit comercial LSA B2 peroxidasa DAB (Dako).

\section{RESUlTADos}

La serie de cincuenta y tres pacientes estaba compuesta por treinta y ocho mujeres y quince hombres, que tenían un promedio etario de 55 años (28-76) y una evolución media de la enfermedad (HASM/TSP) de 8 años (2-28), en el momento que se tomó la muestra de glándulas salivares. En más de la mitad de los pacientes, 30 casos, se observó la presencia de linfocitos anormales (1 a $7 \%$ de linfocitos escotados o lobulados) y en siete de estos pacientes, se demostró la presencia de linfoma hematológico o cutáneo (biopsia de piel), lo que representa 13,2\% de linfomas asociados a HAM/TSP en esta serie. Había seis enfermos con antecedentes de disfunción hepática sin causa definida (11,3\%). Tres de ellos llegaron al estudio anátomo-patológico, demostran- 
do alteraciones histológicas compatibles con una hepatopatía crónica. Otras patologías asociadas a este grupo de pacientes fueron: broncoalveolitis en dos pacientes, artropatía en uno, cistitis hemorrágica en dos, enfermedades que se han descrito asociadas al HTLV-I, así como osteoporosis en 21 de 35 casos en los que se estudio la densidad ósea (60\%). Ninguno de los 53 SS padecía de alguna colagenopatía y los anticuerpos contra Ro y La fueron negativos. Así como ANA en 25 pacientes que se determinó inicialmente.

En esta serie de HAM/TSP con síndrome sicca, diez pacientes eran serológicamente negativos para HTLV-I. Sin embargo, el estudio con la reacción de polimerasa en cadena (PCR), demostró la presencia del gen Tax. La funcionalidad motora (paraparesia) no se relacionó con el grado de compromiso glandular y la presencia de linfocitos anormales o linfoma, tampoco influyó en el grado del daño glandular. No tenemos el antecedente de si en alguno de estos pacientes, el síndrome sicca se inició antes que la paraparesia.

El estudio histológico reveló, de acuerdo a la clasificación de Chisholm y Mason, que en nueve pacientes se observó un grado máximo (4), veintisiete tenían grado $3 \mathrm{y}$ diecisiete grado 2 (Figura 1). Los linfocitos identificados eran predominantemente $\mathrm{CD} 8$, en un abundante contexto de CD45 (Figura 2), los linfocitos CD4 se observaron especialmente en sectores perivasculares. La MMP-9 se expresaba en la proximidad de la lámina basal de la glándula y en algunos acinos (Figura 3A). La presencia de la proteína Tax se observó en linfocitos CD4 y CD8 y se detectó en algunas células plasmáticas (Figura 3B).

La presencia de Tax se vio en el citoplasma paranuclear de las células glandulares, particularmente en las células basales de los acinos; como si la proteína Tax se expresara especialmente en las etapas de proliferación glandular, para decaer en el proceso de la maduración secretoria (Figura 4). Tres pacientes con estudio anatomopatológico en los que se pudo analizar el hígado por histoquímica, mostraron al igual que en sus glándulas salivares, la presencia de acúmulos de CD8 y CD 45 repartidos en el parénquima y en el área centrolobulillar. Además, se observó expresión de Tax en las células hepáticas, en áreas próximas al

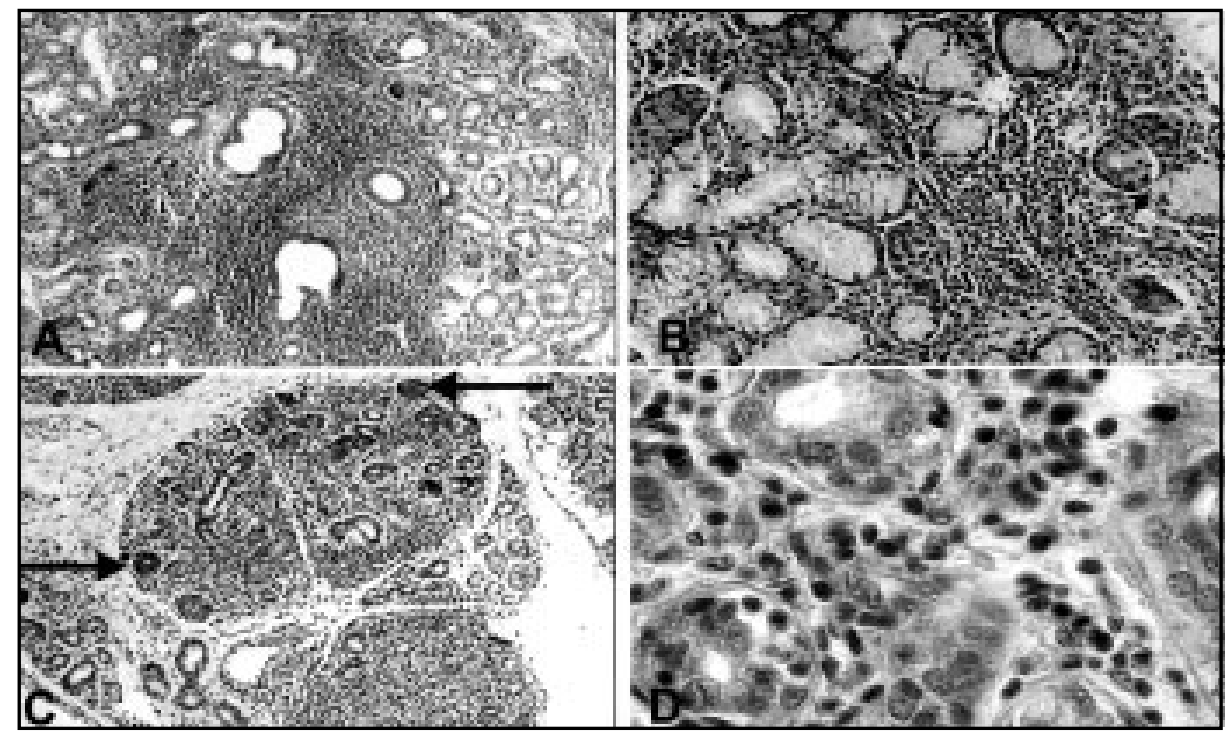

Figura 1. Glándulas salivares menores.

A) Alteración grado 4 de acuerdo a Chisholm y Mason. Infiltrado periductal de linfocitos, HE X 5O; B) Infiltrado linfocitario intersticial, HE X 100; C) Ascinos glandulares activos (flechas) entre un severo infiltrado linfocitario, hematoxilina mucina X 50; D) Células glandulares desprendidas de la membrana basal invasión de este espacio por linfocitos, HE X 200. 


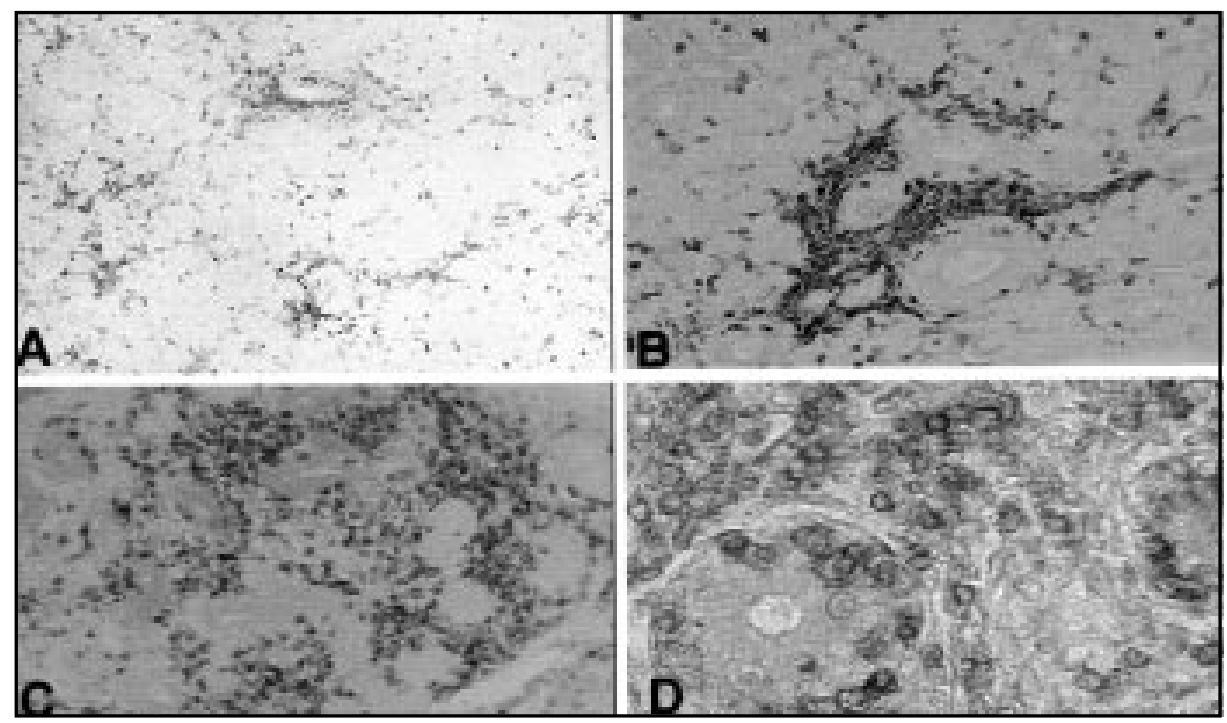

Figura 2. Glándulas salivares menores.

A) Linfocitos CD45 en sectores perivasculares, antiCD45 X 50; B) Anti CD45 X 100; C) Linfocitos CD8 distribución intersticial, antiCD 8 X 100; D) Linfocitos CD8 que invaden el ascino glandular, desprendimiento de células glandulares de la membrana basal, antiCD8 X 200.

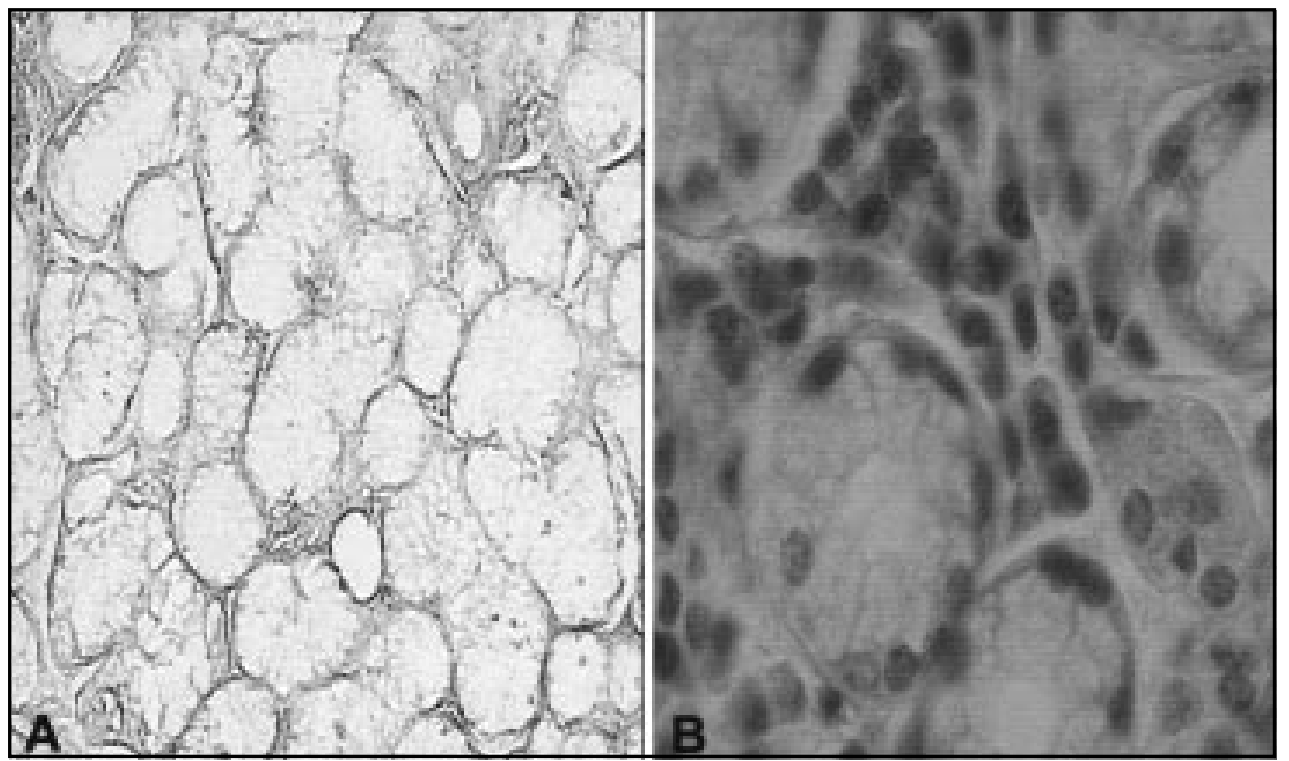

Figura 3. Glándulas salivares menores.

A) Enzima matricial MMB-9 visible en la membrana basal, anti MMP-9 X 100; B) Linfocitos que expresan Tax, anti Tax-hematoxilina X 200. 
núcleo de los hepatocitos (Figura 5). No se encontró proteína Tax y la actividad de MMP-9 también fue irrelevante en los casos controles.

\section{DisCUSIÓN}

La preferencia del HTLV-I por las glándulas exocrinas, tiene el antecedente clínico de su presencia en las glándulas mamarias, origen y fuente de la transmisión del virus a través de la lactancia. Se ha observado experimentalmente que el HTLV-I es capaz de infectar las células mamarias, la glándula infectada representa la posibilidad de un reservorio para el virus, hecho que permite su transmisión por mujeres embarazadas, portadoras sanas ${ }^{10}$.

La alta prevalencia del síndrome de Sjögren entre pacientes con HAM/TSP se puso en eviden-

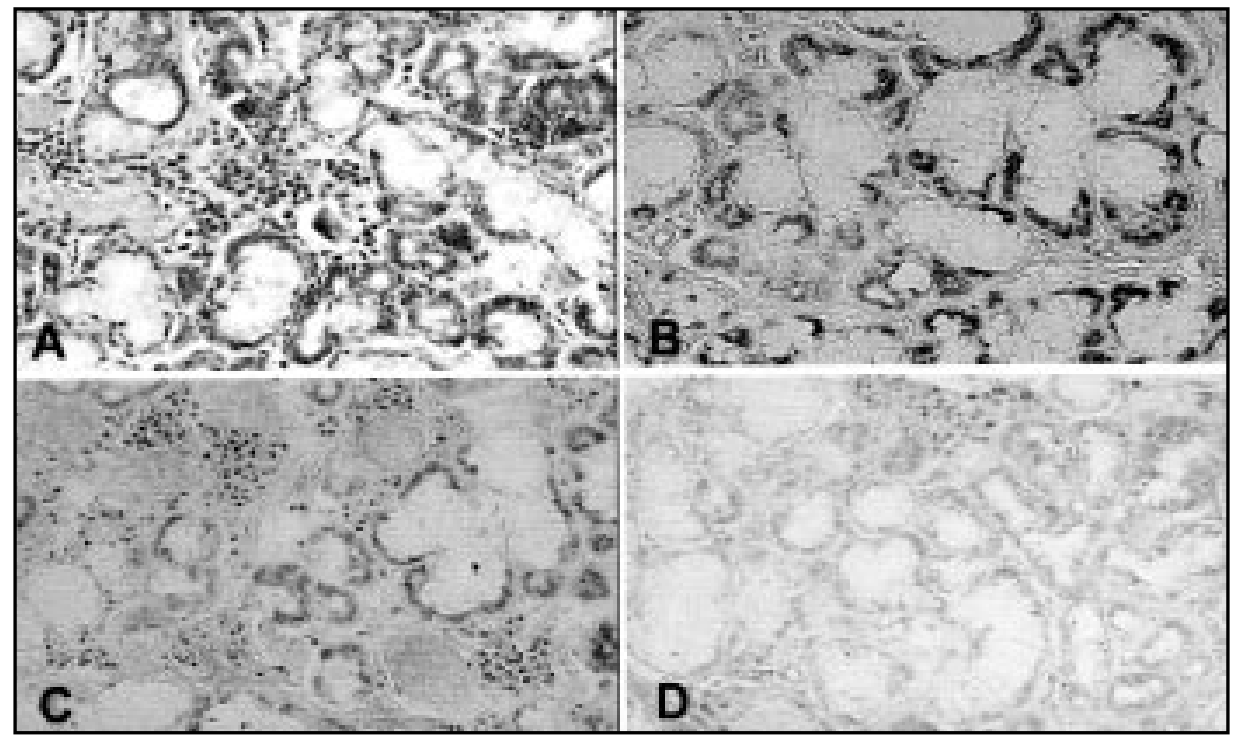

Figura 4. Glándulas salivares menores.

A, C, D) Expresión de Tax en linfocitos CD4 y CD8 en infiltrados intersticiales, antiTax X 50; A,B,C,D) Expresión de Tax en células glandulares, región paranuclear, anti Tax X 50.

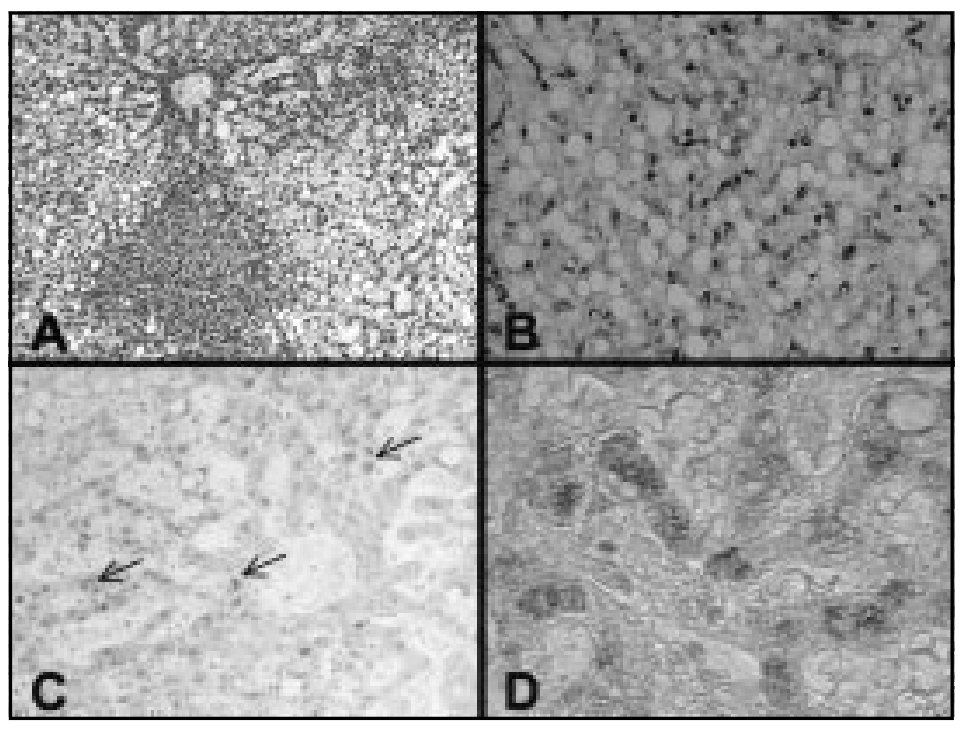

FiguRA 5. Parénquima hepático.

A) Degeneración grasa, infiltrados linfocitarios intersticiales y centro lobulillares, HE X 50; B) Linfocitos CD45 en el parénquima hepático, antiCD45 $\mathrm{X}$ 100; C) Expresión de Tax en los hepatocitos, antiTax X 50; D) Expresión de Tax perinuclear, antiTax X 200 
cia en las primeras observaciones de la enferme$\operatorname{dad}^{11}$ y ha sido informada en distintas publicaciones posteriores, en una proporción de entre $30 \%$ y $60 \%$ de los HAM/TSP 8,12 . El síndrome sicca ha sido relacionado patogénicamente con la presencia del gen Tax. El hallazgo de anticuerpos contra el virus en el suero y saliva de los enfermos con SS avalaría esta relación ${ }^{13}$. Incluso en pacientes que, siendo seronegativos para HTLV-I, han evidenciado la presencia de Tax por PCR, como se ha observado en $19 \%$ de esta serie. Es posible que los pacientes seronegativos para HTLV-I y que son Tax positivos, dispongan de un virus defectual 0 tengan una baja respuesta antigénica que impide su detección, pero que no les impide enfermar ${ }^{14}$. La seronegatividad y la presencia de Tax también ha sido demostrada por otros investigadores ${ }^{15}$. Por su parte, Tangy y col, encontraron el virus en biopsias de glándulas salivares ${ }^{16}$. Además, pareciera ser que la presencia del virus puede extenderse a otras glándulas exocrinas de mucosas y piel $^{17}$.

Esta preferencia del HTLV-I por las glándulas exocrinas, también ha sido puesta en evidencia de manera experimental en ratones transgénicos vinculados al gen Tax del HTLV-I. Estos animales desarrollaron un síndrome semejante al SS, en los cuales las células glandulares expresaban Tax, donde además se observaba daño en los ascinos glandulares, de manera parecida a lo encontrado en esta serie ${ }^{18}$.

Desde un punto de vista inmunológico la ausencia de Ro y La en esta forma de SS no resulta extraña, si se comprende que el factor patogénico de este síndrome sicca sería una proteína viral que puede actuar directa o indirectamente. Por otra parte, estos anticuerpos en la forma primaria de SS tienen, en el caso del anti Ro/SSA, una respuesta de $10 \%$ a $37 \%$ y en el anti La/SSB entre $58 \%$ y $86 \% 18$

La búsqueda sistemática del SS en la hepatitis $\mathrm{C}^{5}$, como lo hemos hecho en los HAM/TSP, ha demostrado que estas formas virales del SS son clínicamente difíciles de distinguir del SS primario. Por ello nos pareció necesario establecer las características clínico-patológicas de esta forma viral del síndrome sicca.

Desde el punto de vista patogénico, se ha valorado la presencia de una enzima de la matriz extracelular, MMP-9, observada en la membrana basal de los acinos glandulares de los SS primarios $^{20}$. En el HAM/TSP el aumento de enzimas de la matriz extracelular es un fenómeno que no sólo puede dar cuenta del daño glandular, sino que también del daño neurológico ${ }^{21}$. La sobreexpresión de MMP-2, MMP-9 y MMP-3 en el líquido cefalorraquídeo de estos pacientes, así como el aumento de los inhibidores naturales como TIM-1TIM-2 y TIM-321, son concordantes con la expresión de MMP-9 en las glándulas salivares de los HAM/TSP, así como de la posible intervención de esta enzima en las alteraciones estructurales y funcionales ${ }^{20,22}$.

Estas formas de síndrome sicca están asociadas a la presencia de Tax en linfocitos y ascinos glandulares, las proteínas virales podrían generar una secuencia antigénica endógena que cronifique el proceso, como ha postulado Mason, respecto de la hepatitis. Pudiendo activar el virus HTLV-I la producción de anticuerpos de una manera parecida a como se supone intervendría el virus de la hepatitis $C$, que desencadenaría desde las glándulas salivares como del parénquima hepático la reacción antigénica ${ }^{23}$. Sin embargo, no deben desecharse otros factores como la reconocida capacidad oncogénica de Tax que conlleva una condición antiapoptótica, que prolonga la vida de los linfocitos y aumenta su capacidad de adhesión celular, hecho que puede resultar relevante en los cambios histológicos de los parénquimas glandulares y hepáticos en las infecciones por HTLV-I ${ }^{24}$. Aunque, la apoptosis de las células glandulares parece ocurrir con independencia de los linfocitos activados, como habría sido observado en el SS primario ${ }^{20}$. En esta forma de síndrome sicca la proteína Tax podría tener una intervención patogénica directa, llevando a la apoptosis de las células glandulares. La polivalencia de la proteína Tax, la puede llevar a ser tanto antiapoptótica como apoptótica, dependiendo de la vinculación que Tax tenga con distintos complejos de proteínas y a la oportunidad del fenómeno ${ }^{25,26}$.

Esta polivalencia del HTLV-I también se observa en las manifestaciones clínicas por su simultánea condición oncogénica (ATL), degenerativa (HAM/ TSP) e inflamatoria (SS) condición que se puede reconocer en varios enfermos de esta serie y en otros previamente descritos ${ }^{11,27}$. Esta convergencia de varias enfermedades simultáneas, originadas por 
un solo agente etiológico, permite comprender la importancia de la intervención del HTLV-I y en particular de Tax, en el metabolismo celular del huésped. Esta intervención del virus tiene como principal propósito lograr condiciones reproductivas. Creemos que las enfermedades serían el producto de esta alteración de funciones, en busca de la propagación del HTLV-I, más que el producto de una respuesta antigénica del huésped. La forma particular de propagación de este virus que necesita del contacto de célula a célula para transmitirse, requiere de toda una estrategia biomolecular, que

\section{REFERENCIAS}

1. Li HC, Fujiroshi T, Lou H, Yashiki S, Sonoda $\mathrm{S}$, CARTiER L et al. The presence of ancient human Tcell lymphotropic virus type I provirus DNA in an Andean mummy. Nature Med 1999; 5: 1428-31.

2. Hinuma $Y$, Nagata $K$, Hanaoka M, Nakai M, Matzuмото T, Kinoshita K et al. Adult T-cell leucemia: Antigens in an HTL cell live and detection of antibodies to the antigen in human sera. Proc Nath Acad Sci USA 1981; 78: 6476-80.

3. Gessain A, Barin E, Vernant JC, Gout O, Maurs L, Calender A et al. Antibodies to human T-lymphotropic virus type-1 in patients with tropical spastic paraparesis. Lancet 1985: 407-10.

4. Cartier L, Castiwo JL, Cea LG, Vimagra R Chronic dacryosialadenitis in HTLV-I associated myelopathy. J Neurol Neurosurg Psychiatry 1995; 58: 2446.

5. Loustaud-Ratti V, Riche A, Lozon E, Labrousse $F$, Soria P, Rogez S et al. Prevalence and characteristics of Sjögren's syndrome or Sicca syndrome in chronic hepatitis $\mathrm{C}$ virus infections: a prospective study. J Rheumatol 2001; 28: 2245-51.

6. Cartier L, mora C, Araya F, Castilo JL, Verdugo R, Milier MA et AL. HTLV-I positive spastic paraparesis in a temperate zone. Lancet 1989; 11: 556-7.

7. Cartier L, Cea JG, Vergara C, Araya F, Born P. Clinical and neuropathological study of six patients with spastic paraparesis associated with HTLV-I: an axomyelinic degeneration of the central nervous system. J Neuropathol Exp Neurol 1997; 56: 403-13. incluye el aumento de células huéspedes, induciendo la proliferación de linfocitos $\mathrm{T}^{28}$; así como la exaltación de factores de adhesión celular, como la activación de las integrinas de la matriz extracelular, con lo que se logra la agregación de los linfocitos y la puesta en marcha de semaforinas, alguna de las cuales tienen un efecto apoptótico ${ }^{29}$. Estas acciones inherentes al virus, no son siempre dependientes de respuestas inmunológicas. Por ello la definición del síndrome sicca producido por el HTLV-I permite establecer una forma singular de este síndrome.

8. Cartier L, Ramírez R, Galeno H. HTLV-I Tax gene on the etiological identification of tropical spastic paraparesis. A clinical, serological and polymerasa chain reaction (PCR) study in 72 patients. Rev Méd Chile 1999; 127: 945-52.

9. Vital C, Bombardieri S, Mautsopoulos HM, Col J, GerL R, Hatron PY et al. Assessment of the European classification criteria for Sjögren's syndrome in a series of clinically defined cases: results of a prospective multicentre study. The European Study Group on Diagnostic Criteria for Sjögren's syndrome. Ann Rheum Dis 1996; 55: 116-21.

10. Souther SO, Southem PJ. Persistent HTLV-I infection of breast luminal epithelial cells: A role in HTLV transmission. Virology 1998; 241: 200-14.

11. Vernant JC, Buisson G, Magdeleine J, De Thore J, Jonannelie A, Neisson-Vernant C et al. T-lymphocyte alveolitis, tropical spastic paraparesis and Sjögren syndrome. Lancet 1988; i: 177.

12. Nakamura $H$, Eguchi $K$, Nakamura T, Mizokami A, Shirabe S, KawaKam A et al. High prevalence of Sjögren's syndrome in patients with HTLV-I associated myelopathy. Ann Rheum Dis 1997; 56: 167-72.

13. Terada K, Katamine S, Eguchi, Moriuchi R, Kita M, SHimada H ET AL. Prevalence of serum and salivary antibodies to HTLV-I in Sjögren's syndrome. Lancet 1994; 334: 1116-9.

14. Ramirez E, Fernández J, Cartier L, Viшota C, Ríos M. Defective human T-cell lymphotopic virus type I (HTLV-I) provirus in seronegative tropical spastic paraparesis/HTLV-I associated myelopathy (TSPHAM) patients. Virus Res 2003; 91: 231-9. 
15. Mariette X, Agbalika F, Zucker-Frankun D, Cierc D, Janin A, Cherot P ET AL. Detection of the Tax gene of HTLV-I in labial salivary glands from patients with Sjögren syndrome and other disease of the oral cavity. Clin Exp Rheumatol 2000; 18: 341-7.

16. Tangy F, Ossondo M, Vernant JC, Smadga D, Bletry O, Bagln AC, Ozden S. Human T-cell leukemia virus type 1 expression in salivary glands of infected patients. J Infect Dis 1999; 179: 497-502.

17. Setoyama M, Nizoguchi S, Eizuru Y. Human T-cell lymphotropic virus type 1 infects accrine sweat gland epithelia. Int J Cancer 1999; 80: 652-5.

18. Green JE, Hinrichs SH, Vogel J, Jay G. Exocrinopathy resembling Sjögren's syndrome in HTLV-I Tax transgenic mice. Nature 1989; 341: 72-4.

19. Tzioufas AG, Wassmuth R, Dafni MG, Guials A, Hage HJ, Isenberg DA et al. Clinical inmunologi$\mathrm{cal}$, and immunogenetic aspect of autoantibody production against Ro/SSA, La/SSB and their linear epitopes in primary Sjögren's syndrome (pSS): a European multicentre study. Ann Rheum Dis 2002; 61: 398-404.

20. Goicovich E, Molina C, Pérez P, Aguilera S, FeRnández J, Olea N ET Al. Enhaced degradation of proteins of the basal lamina and stroma by matryx metalloproteinases from the salivary glands of Sjögren's syndrome patients: Correlation with reduced structural integrity of acini and ducts. Arthritis Rheum 2003; 48: 2573-84.

21. Kettlun AM, Cartier L, García L, Collados L, VÁsquez F, RAmírez E et aL. TIMPs and MMPs expression in CSF from patients with TSP/HAM. Life Sciences 2003; 9309: 1-14.
22. Borchers AT, Naguwa SM, Keen CL, Gershwin ME. Immunopathogenesis of Sjögren's syndrome. Clin Rev Allergy Immunol 2003; 25: 89-104.

23. Mason AL, Xu L, Guo L, GaRRY RF. Retroviruses in autoimmune liver disease: genetic or environmental agents. Arch Immunol Ther Exp 1999; 47: 289-97.

24. KaWAKami A, Eguchi R. Involvement of apoptotic cell death in autoinmune disease. Med Electron Microsc 2002; 35: 1-8.

25. Himura $Y$, Nagata $K$, Hanaoka M, Nakai M, Matzuмото T, KINoshita K Eт al. Adult T-cell leukemia: antigenin an ATL cell live and detection of antibodies to the antigen in human sera. Proc Natl Acad Sci USA 1981; 78: 6476-80.

26. Wu K, Bottazzi ME, De La Fuente C, Deng L, Gitun SD, Maddukuri A et al. Protein profile of Taxassociated complexes. J Biol Chemestry 2004; 279: 495-508.

27. Kuroda Y, Fukuoka M, Endo C et al. Occurrence of primary biliary cirrhosis, CREST syndrome and Sjögren's syndrome in a patient with HTLVI associated myelopathy. J Neurol 1993; 116: 4751.

28. YoshiDA M. Multiple viral strategies of HTLV-I for dysregulation of cell growth control. Annu Rev Immunol 2001; 19: 475-96.

29. Giraudon P, Vincent P, Vanilat C, Veriaeten O, Cartier L, Cardine AM et al. Semaphorin CD 100 from activated $\mathrm{T}$ lymphocytes induces process extension collapse in oligodendrocytes and death of immature neural cells. J Immunol 2004; 172: 1246-55. 